\title{
Efficacy of Adjuvant Combination Therapy With Trastuzumab and Chemotherapy in HER2-positive Early Breast Cancer: A Single Institutional Cohort Study from Clinical Practice
}

\author{
MASAHIRO OKAMOTO ${ }^{1}$, WAKAKO TAJIRI ${ }^{1}$, HIROKI UEO ${ }^{1}$, TAKANOBU MASUDA ${ }^{1}$, HIDEKI IJICHI ${ }^{1}$, \\ CHINAMI KOGA ${ }^{1}$, YOSHIAKI NAKAMURA ${ }^{1}$, KENICHI TAGUCHI $^{2}$, SHINJI OHNO $^{3}$ and ERIKO TOKUNAGA ${ }^{1}$ \\ ${ }^{1}$ Department of Breast Oncology, National Hospital Organization Kyushu Cancer Center, Fukuoka, Japan; \\ ${ }^{2}$ Department of Pathology, National Hospital Organization Kyushu Cancer Center, Fukuoka, Japan; \\ ${ }^{3}$ Breast Cancer Center, Cancer Institute Hospital, Tokyo, Japan
}

\begin{abstract}
Background/Aim: To evaluate the improvement in the prognosis by adjuvant trastuzumab in clinical practice and the risk factors for distant recurrence, we retrospectively investigated the prognosis of HER2-positive early breast cancer in our department before and after the introduction of adjuvant trastuzumab. Patients and Methods: Cohorts A and B included 161 and 182 cases, respectively, who underwent surgery before (2000-2007) and after (2008-2015) the introduction of adjuvant trastuzumab. Results: The rates of relapse-free and distant metastasis-free survival were significantly better in cohort $B$ than in cohort $A$. The risk factors of distant recurrence found in cohort A, such as the presence of lymph node metastasis, lymphatic invasion, and a low histological grade, did not increase the risk in cohort B. Conclusion: Many risk factors seemed to have been negated by adjuvant trastuzumab administration. Therefore, further escalation of adjuvant treatment should be carefully considered.
\end{abstract}

The overexpression of human epidermal growth factor-2 (HER2) occurs in approximately $15-20 \%$ of breast cancer patients and is associated with aggressive behavior of the tumor $(1,2)$. Several large randomized trials showed the prognostic benefits of the addition of trastuzumab (TZM) to standard adjuvant chemotherapy in patients with HER2positive early breast cancer (EBC) (3-5). In Japan, 1-year adjuvant TZM for patients undergoing adjuvant

This article is freely accessible online.

Correspondence to: Eriko Tokunaga, MD, Ph.D., Department of Breast Oncology, National Hospital Organization Kyushu Cancer Center, 3-1-1 Notame, Minami-ku, Fukuoka 811-1395, Japan. Tel: +81 925413231, e-mail: eriko.tokunaga.pw@mail.hosp.go.jp

Key Words: Breast cancer, HER2, trastuzumab. chemotherapy was approved for public insurance coverage in 2008 and since then has been widely used to treat HER2positive EBC.

Most data showing the effect of adjuvant TZM have derived from phase 3 clinical trials, in which patients with lymph node positivity or with tumors larger than $10 \mathrm{~mm}$ were eligible $(3,4)$. However, because of the benefits, the indication of adjuvant TZM has been expanded to include patients with smaller tumors and node-negative patients (6). In our department, we usually proposed TZM plus chemotherapy to patients with HER2-positive EBC $>10 \mathrm{~mm}$ in size, regardless of lymph node metastasis. In the case of tumors of 5-10 $\mathrm{mm}$ in size, we considered the use of TZM individually for each patient.

Adjuvant chemotherapy performed with or without TZM for HER2-positive EBC has also been improved. Cyclophosphamide, methotrexate, and fluorouracil (CMF) was the first adjuvant combination therapy for $\operatorname{EBC}(7,8)$, but the effect of CMF was significantly inferior to anthracycline-containing chemotherapy for HER2-positive EBC (9). Because the addition of a taxane sequentially to an anthracycline-based regimen was shown to improve the outcome of high-risk EBC (10), anthracycline-based therapy followed by taxane became the standard chemotherapy combined with TZM $(3,4)$.

The combination of pertuzumab, TZM and docetaxel has been shown to have a significant survival benefit in patients with HER2-positive metastatic breast cancer (11, 12). A similar benefit of pertuzumab was expected in the adjuvant setting and pertuzumab significantly improved the rates of invasive-disease-free survival among patients with HER2positive EBC (13). However, the addition of pertuzumab had only a small effect in the node-negative population and was associated with toxic effects, such as mild diarrhea. The combination of TZM and chemotherapy might be sufficient in low-risk patients. 
Table I. Clinicopathological backgrounds of the patients in cohort A and cohort B.

\begin{tabular}{|c|c|c|c|c|c|}
\hline \multirow[t]{2}{*}{ Characteristics } & \multicolumn{2}{|c|}{ Cohort A $(n=161)$} & \multicolumn{2}{|c|}{ Cohort B $(n=182)$} & \multirow[b]{2}{*}{$p$-Value } \\
\hline & No. & $\%$ & No. & $\%$ & \\
\hline Age mean (SD) & \multicolumn{2}{|c|}{$54.4(9.2)$} & \multicolumn{2}{|c|}{$56.4(10.3)$} & 0.059 \\
\hline \multicolumn{6}{|l|}{ Pathological tumor stage } \\
\hline$-\mathrm{T} 1 \mathrm{~b}$ & 30 & $18.6 \%$ & 40 & $22.0 \%$ & 0.50 \\
\hline T1c- & 130 & $80.7 \%$ & 142 & $78.0 \%$ & \\
\hline Missing & 1 & $0.6 \%$ & 0 & $0.0 \%$ & \\
\hline \multicolumn{6}{|l|}{ Pathological nodal stage } \\
\hline $\mathrm{N}(-)$ & 100 & $62.1 \%$ & 126 & $69.2 \%$ & 0.17 \\
\hline $\mathrm{N}(+)$ & 61 & $37.9 \%$ & 56 & $30.8 \%$ & \\
\hline \multicolumn{6}{|l|}{ Histological grade (HG) } \\
\hline HG1, 2 & 69 & $42.9 \%$ & 76 & $41.8 \%$ & 0.660 \\
\hline HG3 & 87 & $54.0 \%$ & 106 & $58.2 \%$ & \\
\hline Missing & 5 & $3.1 \%$ & 0 & $0.0 \%$ & \\
\hline \multicolumn{6}{|l|}{ ly factor } \\
\hline ly $(-)$ & 104 & $64.6 \%$ & 139 & $76.4 \%$ & 0.018 \\
\hline ly $(+)$ & 57 & $35.4 \%$ & 43 & $23.6 \%$ & \\
\hline \multicolumn{6}{|l|}{$\mathrm{v}$ factor } \\
\hline $\mathrm{v}(-)$ & 145 & $90.1 \%$ & 175 & $96.2 \%$ & 0.030 \\
\hline $\mathrm{v}(+)$ & 16 & $9.9 \%$ & 7 & $3.8 \%$ & \\
\hline \multicolumn{6}{|l|}{ Hormone receptor status } \\
\hline Negative & 89 & $55.3 \%$ & 60 & $33.0 \%$ & $<0.001$ \\
\hline Positive & 72 & $44.7 \%$ & 122 & $67.0 \%$ & \\
\hline $\mathrm{ER}(+), \operatorname{PgR}(+)$ & 41 & $25.5 \%$ & 87 & $47.8 \%$ & $0.016^{* *}$ \\
\hline $\operatorname{ER}(+), \operatorname{PgR}(-)$ & 26 & $16.1 \%$ & 34 & $18.7 \%$ & \\
\hline $\operatorname{ER}(-), \operatorname{PgR}(+)$ & 5 & $3.1 \%$ & 1 & $0.5 \%$ & \\
\hline \multicolumn{6}{|l|}{ Adjuvant endocrine therapy } \\
\hline No & 95 & $59.0 \%$ & 75 & $41.2 \%$ & $0.001 *$ \\
\hline Yes & 66 & $41.0 \%$ & 107 & $58.8 \%$ & \\
\hline SERM & 37 & $23.0 \%$ & 42 & $23.1 \%$ & $0.18^{* *}$ \\
\hline $\mathrm{AI}$ & 39 & $24.2 \%$ & 67 & $36.8 \%$ & \\
\hline \multicolumn{6}{|l|}{ Adjuvant chemotherapy } \\
\hline No & 48 & $29.8 \%$ & 32 & $17.6 \%$ & $0.02 *$ \\
\hline Yes & 113 & $70.2 \%$ & 150 & $82.4 \%$ & \\
\hline $\mathrm{CMF}$ & 15 & $9.3 \%$ & 0 & $0.0 \%$ & $<0.001 * *$ \\
\hline Anthracycline-based & 51 & $31.7 \%$ & 30 & $16.5 \%$ & \\
\hline Taxane-based & 3 & $1.9 \%$ & 9 & $4.9 \%$ & \\
\hline Anthracycline and Taxane & 43 & $26.7 \%$ & 110 & $60.4 \%$ & \\
\hline Others & 1 & $0.6 \%$ & 1 & $0.5 \%$ & \\
\hline \multicolumn{6}{|l|}{ Adjuvant trastuzumab } \\
\hline No & 148 & $91.9 \%$ & 38 & $20.9 \%$ & $<0.001$ \\
\hline Yes & 13 & $8.1 \%$ & 144 & $79.1 \%$ & \\
\hline
\end{tabular}

SERM: Selective estrogen receptor modifier; CMF: cyclophosphamide, methotrexate, and fluorouracil. *Fisher's exact test between "Yes" and "No"; **Fisher's exact test among sub-category.

In this study, we examined the benefit of TZM therapy in real-world practice by comparing the survival rates of HER2positive EBC patients between two different periods; before and after the approval of adjuvant TZM. Moreover, we investigated the risk factors for recurrence in each period in order to determine the subgroup in which the efficacy of TZM-containing chemotherapy would be insufficient and in which more intensive treatment, such as pertuzumab, would be necessary.

\section{Patients and Methods}

Patient population. We identified all pathological stage I-III EBC patients who underwent surgery without neoadjuvant systemic therapy for primary breast cancer in the Department of Breast Oncology, National Hospital Organization Kyushu Cancer Center between 2000 and 2015. Among them, patients aged $\leq 75$ years with HER2-positive EBC were included in this study. The clinical data were obtained from the patients' medical records. The AJCC/UICC TNM classification and stage groupings were used. Written 
Table II. Adjuvant systemic treatments in each cohort.

\begin{tabular}{|c|c|c|c|c|c|c|c|c|c|c|c|c|c|c|c|c|c|c|c|}
\hline & \multicolumn{9}{|c|}{ Cohort A $(n=161)$} & \multicolumn{9}{|c|}{ Cohort B $(n=182)$} & \multirow{3}{*}{$p$-Value $*:$} \\
\hline & \multicolumn{2}{|c|}{ CT (-) } & \multicolumn{2}{|c|}{$\mathrm{CT}(+)$} & \multirow[t]{2}{*}{$p$-Value* } & \multicolumn{4}{|c|}{$\mathrm{CT}(+)$} & \multicolumn{2}{|c|}{ CT (-) } & \multirow{2}{*}{\multicolumn{2}{|c|}{$\mathrm{CT}(+)$}} & \multirow[t]{2}{*}{$p$-Value* } & \multicolumn{4}{|c|}{$\mathrm{CT}(+)$} & \\
\hline & & & & & & $\mathrm{TZI}$ & $M(-)$ & & $M(+)$ & & & & & & & M (-) & $\mathrm{T} 2$ & $\mathrm{M}(+)$ & \\
\hline \multicolumn{20}{|l|}{ pT stage } \\
\hline$-\mathrm{T} 1 \mathrm{~b}$ & 20 & $66.7 \%$ & 10 & $33.3 \%$ & $<0.001$ & 10 & $33.3 \%$ & 0 & $0.0 \%$ & 23 & $57.5 \%$ & 17 & $42.5 \%$ & $<0.001$ & 1 & $2.5 \%$ & 16 & $40.0 \%$ & 0.65 \\
\hline $\begin{array}{c}\text { T1c- } \\
\text { pN stage }\end{array}$ & 25 & $19.2 \%$ & 105 & $80.8 \%$ & & 92 & $70.8 \%$ & 13 & $10.0 \%$ & 9 & $6.3 \%$ & 133 & $93.7 \%$ & & 5 & $3.5 \%$ & 128 & $90.1 \%$ & 0.002 \\
\hline $\mathrm{N}(-)$ & 43 & $43.0 \%$ & 57 & $57.0 \%$ & $<0.001$ & 52 & $52.0 \%$ & 5 & $5.0 \%$ & 28 & $22.2 \%$ & 98 & $77.8 \%$ & 0.019 & 4 & $3.2 \%$ & 94 & $74.6 \%$ & $<0.001$ \\
\hline $\mathrm{N}(+)$ & 3 & $4.9 \%$ & 58 & $95.1 \%$ & & 50 & $82.0 \%$ & 8 & $13.1 \%$ & 4 & $7.1 \%$ & 52 & $92.9 \%$ & & 2 & $3.6 \%$ & 50 & $89.3 \%$ & 0.71 \\
\hline \multicolumn{20}{|l|}{ HG } \\
\hline HG1, 2 & 26 & $37.7 \%$ & 43 & $62.3 \%$ & 0.053 & 39 & $56.5 \%$ & 4 & $5.8 \%$ & 20 & $26.3 \%$ & 56 & $73.7 \%$ & 0.011 & 1 & $1.3 \%$ & 55 & $72.4 \%$ & 0.16 \\
\hline HG3 & 20 & $23.0 \%$ & 67 & $77.0 \%$ & & 58 & $66.7 \%$ & 9 & $10.3 \%$ & 12 & $11.3 \%$ & 94 & $88.7 \%$ & & 5 & $4.7 \%$ & 89 & $84.0 \%$ & 0.034 \\
\hline \multicolumn{20}{|l|}{ HR } \\
\hline Negative & 18 & $20.2 \%$ & 71 & $79.8 \%$ & 0.014 & 63 & $70.8 \%$ & 8 & $9.0 \%$ & 10 & $16.7 \%$ & 50 & $83.3 \%$ & 1 & 3 & $5.0 \%$ & 47 & $78.3 \%$ & 0.67 \\
\hline Positive & 28 & $38.9 \%$ & 44 & $61.1 \%$ & & 39 & $54.2 \%$ & 5 & $6.9 \%$ & 22 & $18.0 \%$ & 100 & $82.0 \%$ & & 3 & $2.5 \%$ & 97 & $79.5 \%$ & 0.002 \\
\hline
\end{tabular}

CT: Chemotherapy; TZM: trastuzumab; HG: histological grade; HR: hormone receptor. *Fisher's exact test comparing between factors; **Fisher's exact test comparing between cohorts (Cohort A vs. Cohort B).

informed consent was obtained from all patients before collecting tissue samples. This study was approved by the institutional review board of our hospital.

The expression of estrogen receptor (ER) and progesterone receptor $(\mathrm{PgR})$ were regarded as positive if their nuclear expression was $\geq 1 \%$ and hormone receptor (HR) was regarded as positive in cases that were either ER-positive or PgR-positive. The HER2 status was evaluated according to the recommendations of ASCO/CAP (14).

Patients were divided into two groups, cohort A and cohort B, according to the year of surgery. Patients in cohort A underwent breast cancer surgery from 2000 to 2007 (when TZM was not used in the adjuvant setting outside clinical trials). Patients in cohort B underwent breast cancer surgery from 2008 to 2015 (when it became possible to use TZM in the adjuvant setting).

Statistical analyses. The statistical analyses were performed using EZR (Saitama Medical Center, Jichi Medical University, Saitama, Japan), which is a graphical user interface for the R software program (The R Foundation for Statistical Computing, Vienna, Austria) (15). The average of age was compared between the cohorts using a $t$-test. Fisher's exact tests were used to compare the proportions of categorical variables. Relapse-free survival (RFS) was defined as the time from surgery to the first breast cancer event, including loco-regional recurrence, distant metastasis, or the development of a new cancer in the contralateral breast. Distant metastasis-free survival (DMFS) was defined as the time from surgery until the development of distant metastasis. Overall survival (OS) was defined as the time from surgery to death from any cause. Survival was estimated using the Kaplan-Meier method and the estimated survival in each clinicopathological subgroup was compared using the log-rank test. $p$-Values of $<0.05$ were considered to indicate statistical significance. A Cox proportional hazards model was used to perform univariate and multivariate analyses of risk factors. Baseline variables with $p<0.05$ in univariate analysis were included in the multivariable models.

\section{Results}

Patient characteristics. We identified 343 patients of 75 years of age or younger who were diagnosed with pathological stage I-III HER2-positive EBC and who underwent surgery without neoadjuvant treatment in our department between 2000 and 2015. Table I shows the clinicopathological characteristics of the study population in cohorts A $(n=161)$ and B $(n=182)$. Patients in cohort A showed more frequently lymphovascular invasion. Patients in cohort B showed more frequently HR positivity, and more frequently received adjuvant endocrine therapy. In cohort A, $71.4 \%$ of patients received postoperative chemotherapy, but only $8.1 \%$ of the patients received TZM-containing therapy. In group B, $79.1 \%$ of patients received TZM-containing postoperative chemotherapy. In addition to the percentage of patients who received chemotherapy, the contents of adjuvant chemotherapy differed between the two cohorts. In the cohort A, anthracycline and taxane-based chemotherapy was administered only in $26.7 \%$ of the patients, but in the cohort B, anthracycline and taxane-based chemotherapy was administered in $60.4 \%$ of the patients. The CMF regimen was not chosen in cohort B. Low histological grade (HG) was significantly associated with HR positivity in both cohorts $(p<0.001$, data not shown).

In cohort $\mathrm{A}$, postoperative chemotherapy (including a small number of patients who received combination therapy with TZM) was more often used for patients with a large tumor size, lymph node metastasis, and HR negativity (Table II). In cohort B, except for patients with a small (-T1b) tumor size, TZM-containing chemotherapy was used. The 


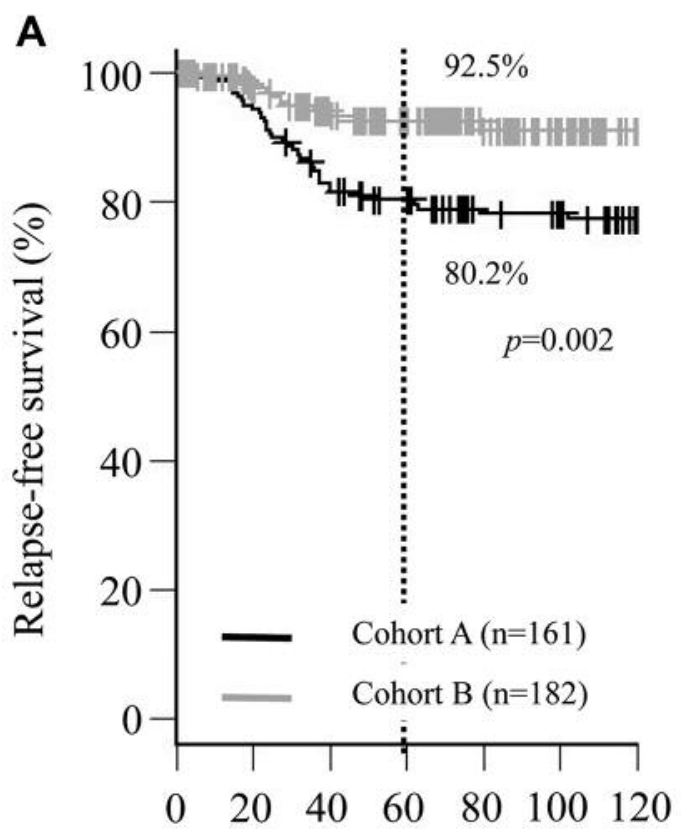

Time from surgery (months)
B

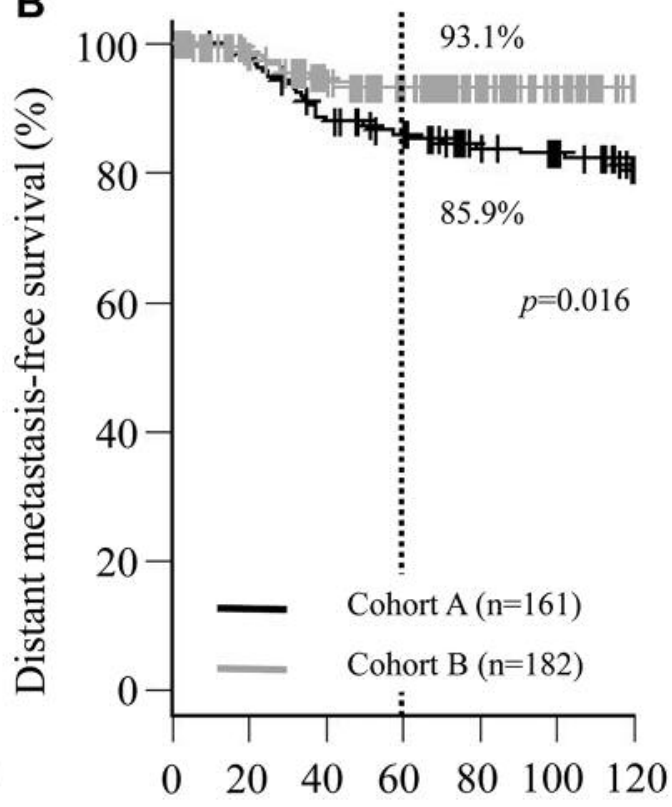

Time from surgery (months)

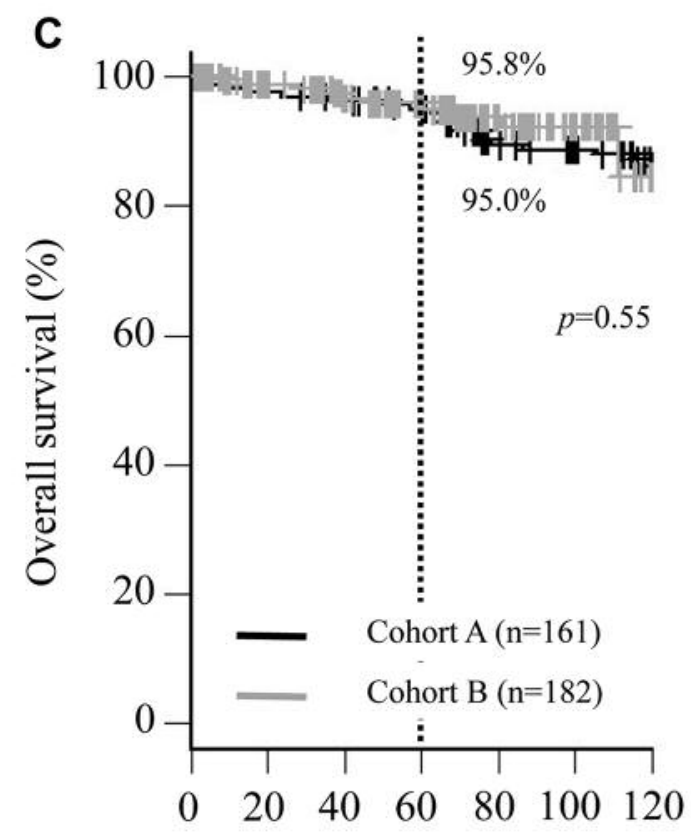

Time from surgery (months)

Figure 1. Kaplan-Meier plots in each cohort for relapse-free survival (A), distant metastasis-free survival (B), and overall survival (C). p-Values were determined by a log-rank test. Five-year survival rates are shown.

HR expression did not influence the application of chemotherapy in cohort B. Chemotherapy without TZM was selected in exceptional cases in cohort B. The comparison of cohort B with cohort A showed that the introduction of chemotherapy (with or without TZM) was significantly increased in the subgroups of patients with large-size tumors, patients without lymph node metastasis, patients with high HG and patients with HR positivity (Table II). 
Table III. Risk factors for distant metastasis in cohort A.

\begin{tabular}{|c|c|c|c|c|c|c|c|}
\hline \multirow[t]{2}{*}{ Factors } & & \multicolumn{3}{|c|}{ Univariate analysis } & \multicolumn{3}{|c|}{ Multivariate analysis } \\
\hline & & Hazard ratio & $95 \% \mathrm{CI}$ & $p$-Value & Hazard ratio & $95 \% \mathrm{CI}$ & $p$-Value \\
\hline pT stage & $\mathrm{T} 1 \mathrm{c}-v s .-\mathrm{T} 1 \mathrm{~b}$ & 3.480 & $0.827-14.64$ & 0.09 & & & \\
\hline \multirow[t]{3}{*}{ pN stage } & $\mathrm{N}(+) v s . \mathrm{N}(-)$ & 6.226 & $2.668-14.53$ & $<0.001$ & 3.668 & $1.368-9.831$ & 0.010 \\
\hline & $\mathrm{N} 2-3$ vs. N0-1 & 2.376 & $1.005-5.353$ & 0.037 & & & \\
\hline & $\mathrm{N} 3$ vs. N0-2 & 2.833 & $0.984-8.158$ & 0.057 & & & \\
\hline Histological grade (HG) & HG3 vs. HG1,2 & 0.447 & $0.212-0.943$ & 0.034 & 0.412 & $0.190-0.892$ & 0.024 \\
\hline ly & ly $(+) v s .1 y(-)$ & 3.826 & $1.817-8.057$ & $<0.001$ & 2.310 & $0.972-5.505$ & 0.06 \\
\hline $\mathrm{v}$ & $\mathrm{v}(+) v s . \mathrm{v}(-)$ & 3.272 & $1.391-7.694$ & 0.007 & 1.967 & $0.817-4.739$ & 0.1 \\
\hline Hormone receptor (HR) & $\mathrm{HR}(+) v s . \mathrm{HR}(-)$ & 1.898 & $0.914-3.942$ & 0.09 & & & \\
\hline Adjuvant chemotherapy & Yes vs. No & 1.715 & $0.699-4.208$ & 0.2 & & & \\
\hline
\end{tabular}

Table IV. Risk factors for distant metastasis in cohort B.

\begin{tabular}{|c|c|c|c|c|c|c|c|}
\hline \multirow[t]{2}{*}{ Factors } & & \multicolumn{3}{|c|}{ Univariate analysis } & \multicolumn{3}{|c|}{ Multivariate analysis } \\
\hline & & Hazard ratio & $95 \% \mathrm{CI}$ & $p$-Value & Hazard ratio & $95 \% \mathrm{CI}$ & $p$-Value \\
\hline pT stage & $\mathrm{T} 1 \mathrm{c}-v s .-\mathrm{T} 1 \mathrm{~b}$ & 2.198 & $0.279-17.35$ & 0.455 & & & \\
\hline \multirow[t]{3}{*}{$\mathrm{pN}$ stage } & $\mathrm{N}(+) v s . \mathrm{N}(-)$ & 1.360 & $0.384-4.820$ & 0.634 & & & \\
\hline & $\mathrm{N} 2-3$ vs. N0-1 & 3.376 & $0.873-13.06$ & 0.078 & & & \\
\hline & $\mathrm{N} 3$ vs. N0-2 & 4.975 & $1.056-23.44$ & 0.042 & & & \\
\hline Histological grade (HG) & HG3 vs. HG1,2 & 2.437 & $0.517-11.48$ & 0.260 & & & \\
\hline ly & ly (+) vs. ly (-) & 0.794 & $0.168-3.740$ & 0.770 & & & \\
\hline $\mathrm{v}$ & $\mathrm{v}(+) v s . \mathrm{v}(-)$ & 9.511 & $1.994-45.38$ & 0.005 & & & \\
\hline Hormone receptor (HR) & $\mathrm{HR}(+) v s . \mathrm{HR}(-)$ & 0.815 & $0.230-2.888$ & 0.751 & & & \\
\hline Adjuvant chemotherapy & Yes $v s$. No & 0.370 & $0.096-1.431$ & 0.150 & & & \\
\hline
\end{tabular}

Relapse-free survival, distant-metastasis free survival, and overall survival. The estimated 5-year RFS rates in cohorts $\mathrm{A}$ and $\mathrm{B}$ were $80.2 \%$ and $92.5 \%$, respectively (Figure $1 \mathrm{~A}$ ). The 5-year DMFS rates in cohorts A and B were $85.9 \%$ and $93.1 \%$, respectively (Figure 1B). The 5-year OS rates in cohorts A and B were $95.0 \%$ and $95.8 \%$, respectively (Figure 1C). RFS and the DMFS were significantly improved in cohort B in comparison to cohort A in log-rank tests ( $p=0.002$ and $p=0.016$, respectively).

Risk factors for distant metastasis in each period. A univariate analysis indicated that pathological lymph node involvement, low HG, lymphatic invasion and vascular invasion were significantly associated with recurrence with distant metastasis in cohort A (Table III). The HR status was not significantly associated with DMFS; however, the Kaplan-Meier curve of DMFS for the HR-positive group continued to decline over 5 years (Figure 2C). A multivariate analysis identified lymph node involvement and low $\mathrm{HG}$ as independent risk factors for distant metastasis in cohort A. However, vascular invasion was the only risk factor for distant metastasis in cohort B in the univariate and multivariate analyses. In cohort $\mathrm{B}$, we examined whether more extensive lymph node metastasis would worsen DMFS. By comparing patients with pathological stage N2-3 to those with N0-1 or patients with pathological stage $\mathrm{N} 3$ to those with $\mathrm{N} 0-2$, we found that the hazard ratio gradually increased to $3.376(0.873-13.06$, $p=0.078)$ and to $4.975(1.056-23.44, p=0.042)$ (Table IV). The Kaplan-Meier curves of DMFS classified by each risk factor in each periodical cohort are shown in Figure 2.

\section{Discussion}

In this study, we investigated the impact of adjuvant TZM together with improved chemotherapy on the outcomes of HER2-positive EBC in our department by comparing the period before the advent of adjuvant TZM to the period after the advent of adjuvant TZM. We found that overall survival did not significantly improve, but the recurrence rate significantly decreased in the latter period. The benefit of adjuvant TZM with appropriate chemotherapy in HER2-positive EBC was confirmed in real world data from a single institution. 
A

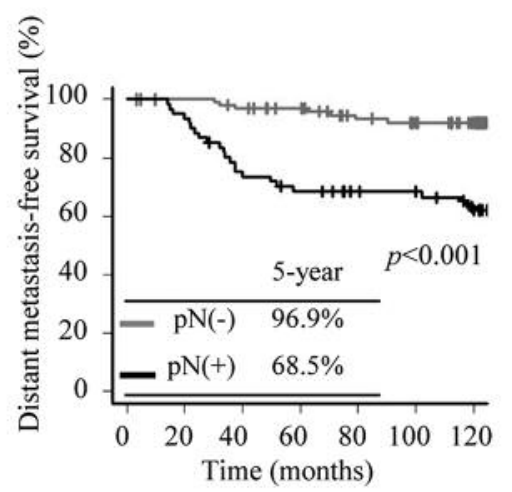

D

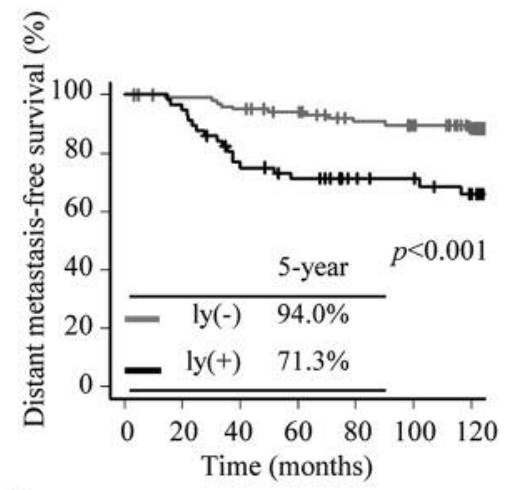

G

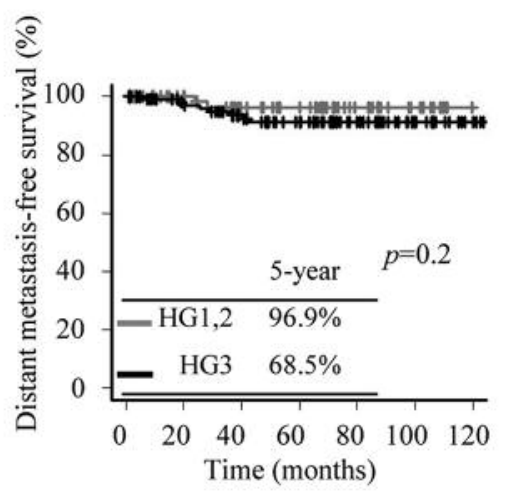

$\mathrm{J}$

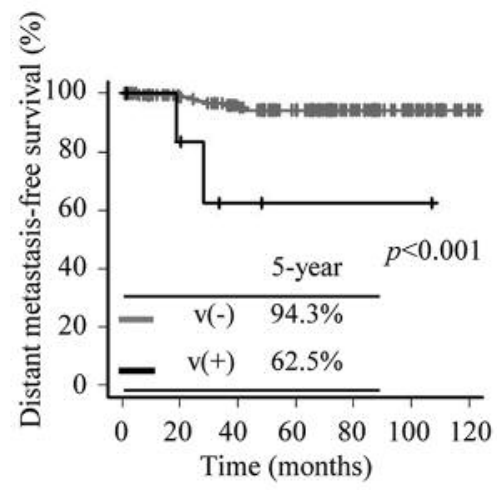

$\mathrm{B}$

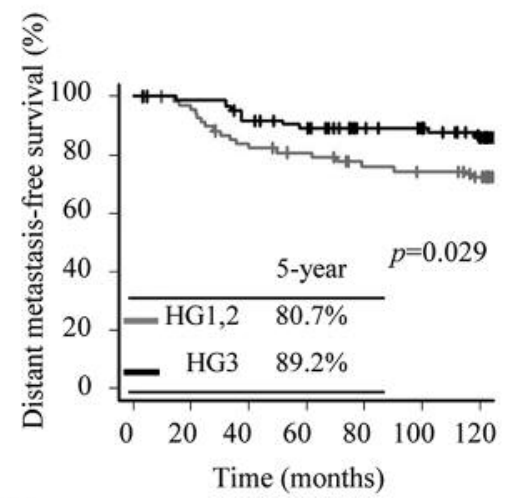

E

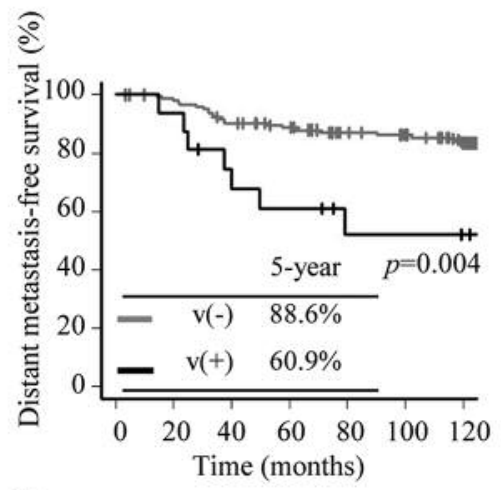

$\mathrm{H}$

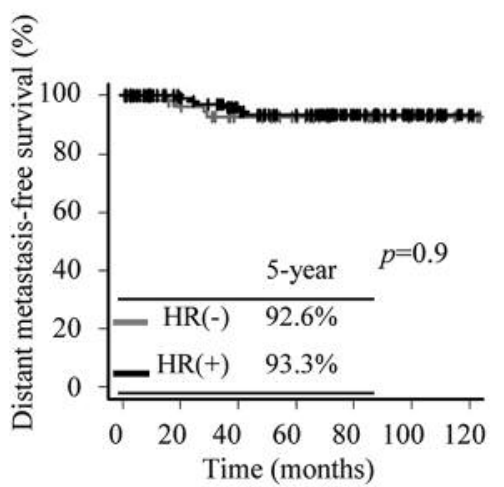

$\mathrm{C}$

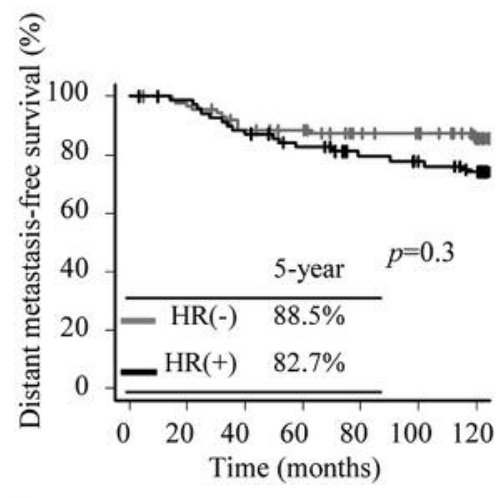

$\mathrm{F}$

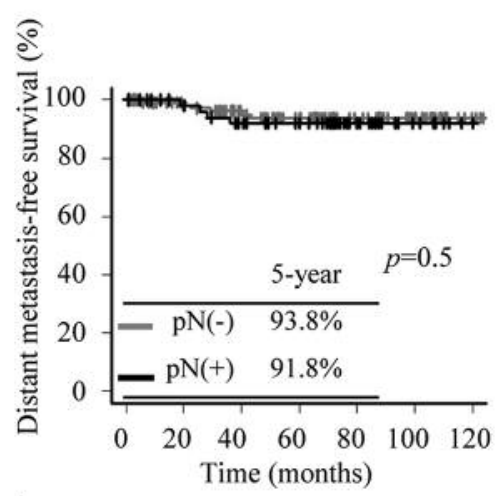

I

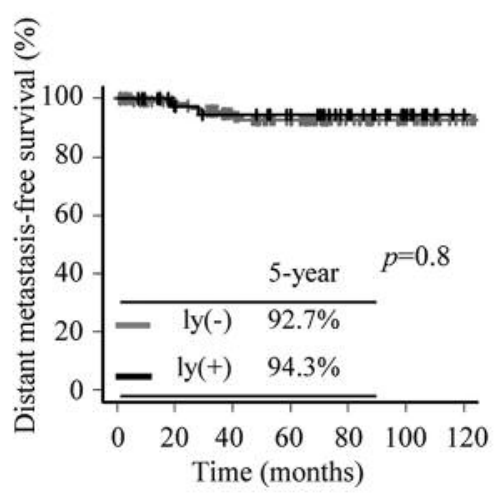

Figure 2. Kaplan-Meier plots for distant metastasis-free survival for cohort A (A-E) and cohort B (F-J). Plots were drawn for subgroups classified by the pathological lymph node status $(A, F)$, histological grade $(B, G)$, hormone receptor status $(C, H)$ lymphatic invasion $(D, I)$, and vascular invasion $(E, J)$. 
Previous studies have shown that many factors, including young age, large tumor size, lymph node metastasis, lymphovascular invasion and high $\mathrm{HG}$ increase the risk of recurrence after primary treatment of $\operatorname{EBC}(16,17)$. In the present study, the results of the univariate analyses showed that the presence of lymph node metastasis, low HG and the presence of lymphatic involvement were risk factors for distant metastasis in the early period. Low HG might be related to resistance to cytotoxic chemotherapy $(18,19)$. However, in the latter period, these factors did not significantly worsen DMFS. Vascular involvement was the only risk factor for metastatic recurrence in both periods.

In HER2-positive EBC, the absence of HR expression has been reported to be a risk factor for recurrence (20). In our study, HR negativity was likely to be a preferable factor of distant recurrence after over 5 years but not significantly, in cohort A.

Recently, new anti-HER2 agents have been developed and escalated adjuvant treatment strategies were considered. In the ExteNET study, the efficacy and safety of 12 months of neratinib, a tyrosine-kinase inhibitor of HER1, HER2, and HER4, after TZM-based adjuvant therapy were investigated in patients with HER2-positive $\operatorname{EBC}(21,22)$. Neratinib could significantly improve 2-year invasive disease-free survival, but some adverse effects, such as diarrhea were observed. In the APHINITY trial, the combination of pertuzumab, TZM and standard chemotherapy could reduce the recurrence of HER2-positive EBC (13). The effect of pertuzumab in low-risk groups, such as node-negative EBC, was very small and chemotherapy combined with TZM alone might be sufficient in this population. In our study, lymph node metastasis was an independent risk factor for recurrence in cohort $\mathrm{A}$. In cohort $\mathrm{B}$, lymph node metastasis was not a risk factor for recurrence; however, the relative risk of distant metastasis gradually increased in association with the pathological lymph node stage. The use of TZM with appropriate chemotherapy has been eliminating the gap in the risk of recurrence due to lymph node metastasis; however, there is probably room to consider more potent treatment in cases with extensive lymph node involvement.

In contrast, studies of de-escalation in adjuvant therapy for HER2-positive EBC have been reported $(6,23-26)$. In the APT trial, 1-year TZM combined with only 12-week paclitaxel was administered for patients with HER2-positive EBC of up to $3 \mathrm{~cm}$ without lymph node metastasis (6). The result was satisfactory, and this regimen was thought to be an option for stage I disease. All trials evaluating the noninferiority of short duration (6 months or 12 weeks) TZM in comparison to 1-year TZM, except for the PERSEPONE study, could not prove non-inferiority; however, there were small differences in survival benefits. However, the possibility of cardiac adverse events apparently decreased in de-escalation groups. We did not choose pre-planned shorter
TZM treatments; however, cases in which TZM cannot be completed due to adverse effects, the discontinuation of TZM might be acceptable.

The present study was associated with some limitations, including its retrospective design. The comparison between two cohorts could be influenced by differences in patient background factors and the changes in the medical environment. However, we intended to show the extent to which the introduction of adjuvant TZM with appropriate chemotherapy could improve the prognosis of high-risk patients in comparison to low-risk patients in clinical practice.

In conclusion, adjuvant TZM could reduce recurrence in HER2-positive EBC patients in a real-world clinical setting and prognostic differences between the high-risk group and the low-risk groups were almost eliminated. We can choose an escalation strategy for high-risk patients, such as those with extensive lymph node metastasis, but with careful consideration of the possible benefits, additional adverse effects and expenses.

\section{Conflicts of Interest}

The Authors have no conflicts of interest regarding the present study.

\section{Authors' Contributions}

M.O., W.T., H.U., T.M., H.I., C.K., Y.N. and K.T. analyzed the data and assisted with data interpretation: M.O. and E.T. conceived the study; M.O. drafted the manuscript; M.O., S.O., and E.T. contributed to discuss and review the final manuscript; all Authors approved the final manuscript.

\section{Acknowledgements}

The Authors would like to thank Ms. Kimiko Baba, Ms. Maki Tanaka and Ms. Yumiko Tatesaka for their valuable assistance.

\section{References}

1 Slamon DJ, Clark GM, Wong SG, Levin WJ, Ullrich A and McGuire WL: Human breast cancer: Correlation of relapse and survival with amplification of the her-2/neu oncogene. Science 235(4785): 177-182, 1987. PMID: 3798106. DOI: 10.1126/ science. 3798106

2 Slamon DJ, Godolphin W, Jones LA, Holt JA, Wong SG, Keith DE, Levin WJ, Stuart SG, Udove J, Ullrich A and Press MF: Studies of the her-2/neu proto-oncogene in human breast and ovarian cancer. Science 244(4905): 707-712, 1989. PMID: 2470152. DOI: $10.1126 /$ science. 2470152

3 Piccart-Gebhart MJ, Procter M, Leyland-Jones B, Goldhirsch A, Untch M, Smith I, Gianni L, Baselga J, Bell R, Jackisch C, Cameron D, Dowsett M, Barrios CH, Steger G, Huang CS, Andersson M, Inbar M, Lichinitser M, Lang I, Nitz U, Iwata H, Thomssen C, Lohrisch C, Suter TM, Ruschoff J, Suto T, Greatorex V, Ward C, Straehle C, McFadden E, Dolci MS, Gelber RD and Herceptin Adjuvant Trial Study T: Trastuzumab 
after adjuvant chemotherapy in her2-positive breast cancer. $\mathrm{N}$ Engl J Med 353(16): 1659-1672, 2005. PMID: 16236737. DOI: 10.1056/NEJMoa052306

4 Romond EH, Perez EA, Bryant J, Suman VJ, Geyer CE, Jr., Davidson NE, Tan-Chiu E, Martino S, Paik S, Kaufman PA, Swain SM, Pisansky TM, Fehrenbacher L, Kutteh LA, Vogel VG, Visscher DW, Yothers G, Jenkins RB, Brown AM, Dakhil SR, Mamounas EP, Lingle WL, Klein PM, Ingle JN and Wolmark N: Trastuzumab plus adjuvant chemotherapy for operable her2positive breast cancer. N Engl J Med 353(16): 1673-1684, 2005. PMID: 16236738. DOI: 10.1056/NEJMoa052122

5 Slamon D, Eiermann W, Robert N, Pienkowski T, Martin M, Press M, Mackey J, Glaspy J, Chan A, Pawlicki M, Pinter T, Valero V, Liu MC, Sauter G, von Minckwitz G, Visco F, Bee V, Buyse M, Bendahmane B, Tabah-Fisch I, Lindsay MA, Riva A, Crown J and Breast Cancer International Research Group: Adjuvant trastuzumab in her2-positive breast cancer. N Engl J Med 365(14): 1273-1283, 2011. PMID: 21991949. DOI: 10.1056/NEJMoa0910383

6 Tolaney SM, Barry WT, Dang CT, Yardley DA, Moy B, Marcom PK, Albain KS, Rugo HS, Ellis M, Shapira I, Wolff AC, Carey LA, Overmoyer BA, Partridge AH, Guo H, Hudis CA, Krop IE, Burstein HJ and Winer EP: Adjuvant paclitaxel and trastuzumab for node-negative, her2-positive breast cancer. N Engl J Med 372(2): 134-141, 2015. PMID: 25564897. DOI: 10.1056/NEJMoa1406281

7 Rossi A, Bonadonna G, Valagussa P and Veronesi U: Adjuvant combination chemotherapy in primary mammary carcinoma: The cmf program. Recent Results Cancer Res 62): 134-142, 1977. PMID: 341246. DOI: 10.1007/978-3-642-81174-6_20

8 Bonadonna G, Rossi A, Valagussa P, Banfi A and Veronesi U: The cmf program for operable breast cancer with positive axillary nodes. Updated analysis on the disease-free interval, site of relapse and drug tolerance. Cancer 39(6 Suppl): 2904-2915, 1977. PMID: 326384. DOI: 10.1002/1097-0142(197706)39:6<2904::aidcncr2820390677>3.0.co;2-8

9 Pritchard KI, Shepherd LE, O'Malley FP, Andrulis IL, Tu D, Bramwell VH, Levine MN and National Cancer Institute of Canada Clinical Trials G: Her2 and responsiveness of breast cancer to adjuvant chemotherapy. N Engl J Med 354(20): 21032111, 2006. PMID: 16707747. DOI: 10.1056/NEJMoa054504

10 De Laurentiis M, Cancello G, D'Agostino D, Giuliano M, Giordano A, Montagna E, Lauria R, Forestieri V, Esposito A, Silvestro L, Pennacchio R, Criscitiello C, Montanino A, Limite G, Bianco AR and De Placido S: Taxane-based combinations as adjuvant chemotherapy of early breast cancer: A meta-analysis of randomized trials. J Clin Oncol 26(1): 44-53, 2008. PMID: 18165639. DOI: 10.1200/JCO.2007.11.3787

11 Baselga J, Cortes J, Kim SB, Im SA, Hegg R, Im YH, Roman L, Pedrini JL, Pienkowski T, Knott A, Clark E, Benyunes MC, Ross G, Swain SM and Group CS: Pertuzumab plus trastuzumab plus docetaxel for metastatic breast cancer. N Engl J Med 366(2): 109119, 2012. PMID: 22149875. DOI: 10.1056/NEJMoa1113216

12 Swain SM, Kim S-B, Cortés J, Ro J, Semiglazov V, Campone M, Ciruelos E, Ferrero JM, Schneeweiss A, Knott A, Clark E, Ross G, Benyunes MC and Baselga J: Pertuzumab, trastuzumab, and docetaxel for her2-positive metastatic breast cancer (cleopatra study): Overall survival results from a randomised, double-blind, placebo-controlled, phase 3 study. Lancet Oncol 14(6): 461-471, 2013. DOI: 10.1016/s1470-2045(13)70130-х

13 von Minckwitz G, Procter M, de Azambuja E, Zardavas D, Benyunes M, Viale G, Suter T, Arahmani A, Rouchet N, Clark
E, Knott A, Lang I, Levy C, Yardley DA, Bines J, Gelber RD, Piccart M, Baselga J, Committee AS and Investigators: Adjuvant pertuzumab and trastuzumab in early her2-positive breast cancer. N Engl J Med 377(2): 122-131, 2017. PMID: 28581356. DOI: 10.1056/NEJMoa1703643

14 Wolff AC, Hammond MEH, Allison KH, Harvey BE, Mangu PB, Bartlett JMS, Bilous M, Ellis IO, Fitzgibbons P, Hanna W, Jenkins RB, Press MF, Spears PA, Vance GH, Viale G, McShane LM and Dowsett M: Human epidermal growth factor receptor 2 testing in breast cancer: American society of clinical oncology/college of american pathologists clinical practice guideline focused update. J Clin Oncol 36(20): 2105-2122, 2018. PMID: 29846122. DOI: 10.1200/JCO.2018.77.8738

15 Kanda Y: Investigation of the freely available easy-to-use software 'ezr' for medical statistics. Bone Marrow Transplant 48(3): 452458, 2013. PMID: 23208313. DOI: 10.1038/bmt.2012.244

16 Haybittle JL, Blamey RW, Elston CW, Johnson J, Doyle PJ, Campbell FC, Nicholson RI and Griffiths K: A prognostic index in primary breast cancer. Br J Cancer 45(3): 361-366, 1982. PMID: 7073932. DOI: 10.1038/bjc.1982.62

17 Goldhirsch A, Ingle JN, Gelber RD, Coates AS, Thurlimann B, Senn HJ and Panel m: Thresholds for therapies: Highlights of the st gallen international expert consensus on the primary therapy of early breast cancer 2009. Ann Oncol 20(8): 13191329, 2009. PMID: 19535820. DOI: 10.1093/annonc/mdp322

18 Tsuda H, Akiyama F, Kurosumi M, Sakamoto G and Watanabe T: Establishment of histological criteria for high-risk node-negative breast carcinoma for a multi-institutional randomized clinical trial of adjuvant therapy. Japan national surgical adjuvant study of breast cancer (nsas-bc) pathology section. Jpn J Clin Oncol 28(8): 486-491, 1998. PMID: 9769782. DOI: 10.1093/jjco/28.8.486

19 Petit T, Wilt M, Velten M, Millon R, Rodier JF, Borel C, Mors R, Haegele P, Eber M and Ghnassia JP: Comparative value of tumour grade, hormonal receptors, ki-67, her-2 and topoisomerase ii alpha status as predictive markers in breast cancer patients treated with neoadjuvant anthracycline-based chemotherapy. Eur J Cancer 40(2): 205-211, 2004. PMID: 14728934. DOI: 10.1016/s0959-8049(03)00675-0

20 Vaz-Luis I, Ottesen RA, Hughes ME, Marcom PK, Moy B, Rugo HS, Theriault RL, Wilson J, Niland JC, Weeks JC and Lin NU: Impact of hormone receptor status on patterns of recurrence and clinical outcomes among patients with human epidermal growth factor-2-positive breast cancer in the national comprehensive cancer network: A prospective cohort study. Breast Cancer Res 14(5): R129, 2012. PMID: 23025714. DOI: 10.1186/bcr3324

21 Chan A, Delaloge S, Holmes FA, Moy B, Iwata H, Harvey VJ, Robert NJ, Silovski T, Gokmen E, von Minckwitz G, Ejlertsen B, Chia SKL, Mansi J, Barrios CH, Gnant M, Buyse M, Gore I, Smith J, 2nd, Harker G, Masuda N, Petrakova K, Zotano AG, Iannotti N, Rodriguez G, Tassone P, Wong A, Bryce R, Ye Y, Yao B, Martin M and Exte NETSG: Neratinib after trastuzumabbased adjuvant therapy in patients with her2-positive breast cancer (extenet): A multicentre, randomised, double-blind, placebo-controlled, phase 3 trial. Lancet Oncol 17(3): 367-377, 2016. PMID: 26874901. DOI: 10.1016/S1470-2045(15)00551-3

22 Martin M, Holmes FA, Ejlertsen B, Delaloge S, Moy B, Iwata $\mathrm{H}$, von Minckwitz G, Chia SKL, Mansi J, Barrios CH, Gnant M, Tomasevic Z, Denduluri N, Separovic R, Gokmen E, Bashford A, Ruiz Borrego M, Kim SB, Jakobsen EH, Ciceniene A, Inoue 
K, Overkamp F, Heijns JB, Armstrong AC, Link JS, Joy AA, Bryce R, Wong A, Moran S, Yao B, Xu F, Auerbach A, Buyse M, Chan A and Exte NETSG: Neratinib after trastuzumab-based adjuvant therapy in her2-positive breast cancer (extenet): 5-year analysis of a randomised, double-blind, placebo-controlled, phase 3 trial. Lancet Oncol 18(12): 1688-1700, 2017. PMID: 29146401. DOI: 10.1016/S1470-2045(17)30717-9

23 Pivot X, Romieu G, Debled M, Pierga JY, Kerbrat P, Bachelot T, Lortholary A, Espie M, Fumoleau P, Serin D, Jacquin JP, Jouannaud C, Rios M, Abadie-Lacourtoisie S, Tubiana-Mathieu N, Cany L, Catala S, Khayat D, Pauporte I, Kramar A and investigators Pt: 6 months versus 12 months of adjuvant trastuzumab for patients with her2-positive early breast cancer (phare): A randomised phase 3 trial. Lancet Oncol 14(8): 741-748, 2013. PMID: 23764181. DOI: 10.1016/S1470-2045(13)70225-0

24 Conte P, Frassoldati A, Bisagni G, Brandes AA, Donadio M, Garrone O, Piacentini F, Cavanna L, Giotta F, Aieta M, Gebbia V, Molino A, Musolino A, Ferro A, Maltoni R, Danese S, Zamagni C, Rimanti A, Cagossi K, Russo A, Pronzato P, Giovanardi F, Moretti G, Lombardo L, Schirone A, Beano A, Amaducci L, Bajardi EA, Vicini R, Balduzzi S, D’Amico R and Guarneri V: Nine weeks versus 1 year adjuvant trastuzumab in combination with chemotherapy: Final results of the phase iii randomized short-her studydouble dagger. Ann Oncol 29(12): 2328-2333, 2018. PMID: 30219886. DOI: 10.1093/annonc/mdy414
25 Joensuu H, Bono P, Kataja V, Alanko T, Kokko R, Asola R, Utriainen T, Turpeenniemi-Hujanen T, Jyrkkio S, Moykkynen K, Helle L, Ingalsuo S, Pajunen M, Huusko M, Salminen T, Auvinen P, Leinonen H, Leinonen M, Isola J and KellokumpuLehtinen PL: Fluorouracil, epirubicin, and cyclophosphamide with either docetaxel or vinorelbine, with or without trastuzumab, as adjuvant treatments of breast cancer: Final results of the finher trial. J Clin Oncol 27(34): 5685-5692, 2009. PMID: 19884557. DOI: 10.1200/JCO.2008.21.4577

26 Earl HM, Hiller L, Vallier AL, Loi S, McAdam K, Hughes-Davies L, Harnett AN, Ah-See ML, Simcock R, Rea D, Raj S, Woodings P, Harries M, Howe D, Raynes K, Higgins HB, Wilcox M, Plummer C, Mansi J, Gounaris I, Mahler-Araujo B, Provenzano E, Chhabra A, Abraham JE, Caldas C, Hall PS, McCabe C, Hulme C, Miles D, Wardley AM, Cameron DA, Dunn JA, Committee PS and Trial I: 6 versus 12 months of adjuvant trastuzumab for her2positive early breast cancer (persephone): 4-year disease-free survival results of a randomised phase 3 non-inferiority trial. Lancet 393(10191): 2599-2612, 2019. PMID: 31178152. DOI: $10.1016 / \mathrm{S} 0140-6736(19) 30650-6$

Received April 22, 2020

Revised May 7, 2020

Accepted May 8, 2020 